\title{
O DIREITO SOCIAL À MORADIA E SUA NECESSÁRIA LIGAÇÃO A OUTROS DIREITOS SOCIAIS: ANÁLISE DO RESIDENCIAL VISTA BELA EM LONDRINA-PARANÁ
}

\author{
Renato César Brambilla ${ }^{1}$ \\ Flávio Pierobon ${ }^{2}$
}

BRAMBILA, R. C.; PIEROBON. F. O direito social à moradia e sua necessária ligação a outros direitos sociais: análise do residencial Vista Bela em LondrinaParaná. Rev. Ciênc. Juríd. Soc. UNIPAR. Umuarama. v. 18, n. 1, p. 25-43, jan./ jun. 2015.

RESUMO: O direito à moradia é um direito fundamental formalmente previsto no Art. $6^{\circ}$ da Constituição Federal de 1988 que não se efetiva apenas com a construção de residências. Importa então desvendar o conceito de "moradia adequada", que abrange, além da habitação, outros elementos essenciais, como o "normal" acesso aos serviços de saúde e de educação, entre outros. Para este trabalho, foi usado como objeto de pesquisa o Residencial Vista Bela, em Londrina, Paraná, no intuito de promover uma pesquisa qualitativa e quantitativa, na medida do possível, utilizando o método hipotético dedutivo. Este residencial é parte de um programa público de moradias populares que ficou conhecido na região de Londrina exatamente por ter sido entregue com flagrante desrespeito àquilo que se pode entender por "moradia adequada".

PALAVRAS-CHAVE: Moradia adequada; Residencial Vista Bela.

\section{INTRODUÇÃO}

O Poder Público, por meio de seus Programas de habitação tem facilitado o acesso às tão "sonhadas" casas próprias à denominada população de baixa renda. $\mathrm{O}$ Direito à moradia tem dimensão constitucional; é um direito arrolado a outros direitos sociais no Art. $6^{\circ}$ da Constituição da República Federativa do Brasil de 1988.

São então formados os Conjuntos Habitacionais compostos por numerosas residências. E, por conseguinte, são alocadas muitas pessoas nestes locais.

Essas pessoas, além do acesso às moradias, necessitam de alguns serviços essenciais, tais como a presença de uma eficiente Unidade Básica de Saúde

DOI: https://doi.org/10.25110/rcjs.v18i1.2015.5408

${ }^{1}$ Graduado em Direito (Faculdade Arthur Thomas de Londrina-Pr FAAT). Pós-Graduando em Direito Constitucional (Instituto de Direito Constitucional e Cidadania de Londrina-Pr IDCC)

${ }^{2}$ Professor de Direito Constitucional da Faculdade Arthur Thomas - FAAT de Londrina, Mestrando em Ciência Jurídica pela Universidade Estadua do Norte do Paraná- UENP, Advogado. 
(UBS), como também de Centros de Educação Infantil (CEI) e da instalação de escolas, garantindo assim, o acesso à saúde e à educação básica, além, é claro, de serviços de transporte coletivo e outras necessidades básicas, como água encanada e luz elétrica.

Os problemas surgirão quando tais residenciais forem construídos, liberados para a ocupação pelos moradores, sem a implantação desses serviços essenciais. A população sofrerá as consequências danosas.

Uma dessas indesejadas consequências ocorrerá, por exemplo, numa família monoparental, contemplada com uma dessas casas, formada pela mãe e seus dois filhos, os quais têm menos de cinco anos de idade. Sem dúvidas, a mãe precisa se lançar ao mercado de trabalho. Aí vem a pergunta: como esta mãe poderá trabalhar se no residencial onde mora, ou nas proximidades, não há o tal Centro de educação Infantil, popularmente conhecido como Creche?

Percebe-se então a necessária ligação entre os direitos sociais previstos no Art. $6^{\circ}$ da Carta Maior de 1988. Com a implantação do Centro de educação Infantil no caso hipotético supracitado, é facilitado o acesso ao trabalho. Poder-se-ia então concluir que, mesmo de forma indireta, estaria o Poder Público garantindo o direito à alimentação, à previdência social, ao lazer, ao fornecer condições de ingresso no mercado de trabalho.

É cediço que há esforços oriundos do Poder Público no sentido de concretizar o direito à moradia àqueles considerados de baixa ou nenhuma renda. Mas pode ser que as moradias construídas a esta população sejam consideradas inadequadas; pode ser que, em muitos casos, não atendam ao princípio da dignidade da pessoa humana.

Será verificado neste trabalho que há casos (exemplificando-se com o Residencial Vista Bela, em Londrina, Paraná) em que tais residenciais são construídos e ocupados desprovidos de alguns serviços essenciais. Serviços como Unidades Básicas de Saúde (UBS), escolas e Centros de educação Infantil (CEI) que possam atender aos moradores de forma eficiente simplesmente inexistem nos bairros ou, ao menos, nas proximidades. É a população local, vulnerável, à mercê da própria sorte.

Outro problema que deve ser colocado é o que se refere às despesas com a manutenção da moradia. Há programas de habitação que proporcionam as moradias mediante financiamentos facilitados, de módicas prestações. Mas, mesmo com essa facilidade, ocorrerá o inadimplemento, caso haja relevantes dificuldades quanto à entrada no mercado de trabalho. Dificuldades advindas do não atendimento de outras necessidades básicas, de outros direitos sociais.

Deverá o Estado assegurar tais direitos. Caso contrário, fatalmente terá de destinar vultosos recursos às populações desses conjuntos habitacionais, mediante programas da área de Assistência Social. 


\section{DIREITO À MORADIA: CLASSIFICAÇÃO E RECONHECIMENTO}

$\mathrm{O}$ incremento do direito à moradia pelo Poder Público brasileiro tem por escopo amenizar a enorme desigualdade de renda aqui existente. É o Estado Democrático Social de Direito, que deve ter uma postura ativa a fim de promover a igualdade material.

Ter acesso à moradia constitui um direito social fundamental. Esses direitos sociais buscam amparar os mais necessitados, a fim de proporcionar-lhes ao menos um patamar mínimo de segurança social.

Oportuno citar aqui os dizeres de Manoel Gonçalves Ferreira Filho (2007, apud OYAMA, 2012, p. 23) quantos aos direitos sociais, ao aduzir que

Entre os meios de atenuação das desigualdades, certamente se inscrevem os direitos sociais. O direito ao trabalho, e os direitos do trabalhador, o direito à educação, à saúde, à moradia, ao lazer, à segurança e à previdência social, por exemplo, que enumera o Art. $6^{\circ}$ da Constituição brasileira, se concretizados, conferem ao povo mais necessitado um mínimo de bem-estar, não apenas condizente com a eminente dignidade humana, mas também ao apego ao regime democrático, no qual foram conquistados. Servem, portanto, de sustentação para a democracia.

O direito social à moradia, introduzido na Constituição Federal de 1988, no Art. $6^{\circ}$, por meio da Emenda constitucional n. 26/2000, devido a sua relevância e característica de fundamentalidade, pode ser considerado tanto um direito humano quanto um direito fundamental. Conforme Ingo Wolfgang Sarlet (2003, p. 194), a caracterização deste direito no rol dos direitos humanos ou no elenco dos direitos fundamentais se refere à sua positivação/situação: se estiver positivado no âmbito de uma Constituição de determinado país, será dito direito fundamental. Se prescrito em documentos internacionais, abrangendo todos os indivíduos, transpondo as fronteiras dos países, será direito humano.

Sarlet (2003, p. 194) leciona que a distinção entre direitos humanos e direitos fundamentais, chancelada por expressiva doutrina, encontra sua razão de ser na existência de diversos planos ou esferas de positivação: usa-se a expressão "direitos fundamentais" àqueles direitos da pessoa positivados no âmbito do Direito Constitucional de um Estado soberano. Por "direitos humanos" são entendidos os que se atribuem a todo ser humano, independentemente de sua vinculação a qualquer Estado (caráter supranacional). E assevera que

Apesar da distinção apontada, [...] verifica-se não haver incompatibilidade [...] entre ambas as categorias (direitos humanos e direitos 
fundamentais), do que dá conta justamente à incorporação ao direito interno, inclusive com hierarquia constitucional, em muitos casos, dos tratados internacionais em matéria de direitos humanos ou mesmo a tendência revelada por expressivo número de constituições modernas, seja no sentido de agasalhar em seu texto expressamente os direitos que vem sendo reconhecidos no plano internacional, seja pela previsão de uma cláusula geral de abertura aos direitos garantidos no direito internacional convencional (SARLET, 2003, p. 196).

O marco do reconhecimento dos direitos econômicos, sociais e culturais (dentre eles o direito à moradia) no plano internacional se deu com a Declaração Universal dos Direitos Humanos da Organização das Nações Unidas (ONU), de 1948. Eis o artigo XXV, 1, desta Declaração:

Artigo XXV. 1. Toda pessoa tem direito a um padrão de vida capaz de assegurar a si e a sua família saúde e bem estar, inclusive alimentação, vestuário, habitação, cuidados médicos e os serviços sociais indispensáveis, e direito à segurança em caso de desemprego, doença, invalidez, viuvez, velhice ou outros casos de perda dos meios de subsistência fora de seu controle. (ONU, 1948, grifo nosso).

Leciona Sarlet (2003, p. 203) que a partir dessa Declaração de 1948, o direito à moradia passou a ser objeto de reconhecimento expresso em outros documentos internacionais. Um destes documentos mais relevantes é o Pacto Internacional dos Direitos Econômicos, Sociais,e Culturais, de 1966.

Tanto a Declaração Universal de Direitos Humanos de 1948 quanto o Pacto Internacional dos Direitos Econômicos, Sociais, e Culturais de 1966 foram ratificados e incorporados ao direito interno brasileiro.

Cumpre ainda mencionar, no âmbito do direito internacional, conforme assinala Sarlet (2003, p.204), “[...] inclusive pela sua influência no que diz com a fundamentação de uma inserção deste direito [direito à moradia] na nossa própria ordem jurídica, na condição de direito fundamental social" a realização de duas grandes conferências promovidas pela ONU que versaram sobre a problemática dos assentamentos urbanos: A Declaração de Vancouver sobre assentamentos urbanos - Habitat I, em 1976 (nesta conferência restou assegurado que a moradia adequada constitui um direito básico da pessoa humana); e em 1996, a Declaração de Istambul - Habitat II (reafirmou-se a característica de direito fundamental ao direito à moradia e previram-se as responsabilidades gerais e específicas dos Estados signatários para o atendimento ao direito à moradia).

No âmbito do direito interno brasileiro, como mencionado, o direito à moradia foi incorporado à Constituição Federal de 1988 (Art. $6^{\circ}$ ) pela Emenda 
26, de 2000 .

Mesmo antes da edição desta Emenda Constitucional era possível vislumbrar menção expressa à moradia em outros dispositivos constitucionais. Um exemplo pode ser encontrado no Art. 23, IX da Carta Maior:

Art. 23.É competência comum da União, dos Estados, do Distrito Federal e dos Municípios:

IX - promover programas de construção de moradias e a melhoria das condições habitacionais e de saneamento básico; (CFRB/88).

Para, além disso, assevera Sarlet (2003, p.206) que

sempre haveria como reconhecer um direito fundamental à moradia como decorrência do princípio da dignidade da pessoa humana (Art. $1^{\circ}$, III, CF/88); [...] já que este reclama, na sua dimensão positiva, a satisfação das necessidades existenciais básicas para uma vida com dignidade, podendo servir até mesmo como fundamento direto e autônomo para o reconhecimento de direitos fundamentais não expressamente positivados, mas inequivocamente destinados à proteção da dignidade.

Portanto, em consonância com Ingo Wolfgang Sarlet e com o citado Art. 23 da Constituição Federal de 1988, é reconhecido o direito à moradia como afirmação da dignidade humana, cabendo a todos os entes governamentais direcionar esforços à ampla concretização desse direito fundamental.

\subsection{CONCEITO DE MORADIA ADEQUADA}

A Constituição Federal de 1988 silenciou acerca de uma definição mínima de um conteúdo para o direito à moradia. Lança-se mão das disposições contidas nos tratados internacionais dos quais o Brasil é signatário. Tais documentos internacionais, naquilo que versam sobre direitos fundamentais, possuem hierarquia constitucional.

O Pacto Internacional dos Direitos Econômicos, Sociais e Culturais de 1966, do qual o Brasil é signatário, prescreve deveres aos Estados-partes visando à concretização da igualdade social, inclusive em relação ao direito a uma moradia adequada. Eis o artigo 11 - 1 deste documento internacional:

Art. 11 - 1. Os Estados - Partes do presente Pacto reconhecem o direito de toda pessoa a um nível de vida adequado para si próprio e sua família, inclusive à alimentação, vestimenta e moradia adequadas, 
assim como a uma melhoria contínua de suas condições de vida. Os Estados - Partes tomarão medidas apropriadas para assegurar a consecução desse direito, reconhecendo, nesse sentido, a importância essencial da cooperação internacional fundada no livre consentimento (ONU, 1966, grifo nosso).

É necessário destacar o Comentário-Geral N.4, $\S 8^{\circ}$, do Comitê da Organização das Nações Unidas (ONU) para Direitos Econômicos, Sociais e Culturais, que identificou uma série de elementos básicos a serem atendidos no tocante ao direito à moradia adequada. São eles:

A) Segurança jurídica na posse, independentemente de sua natureza e origem;

B) Disponibilidade de infraestrutura básica para a garantia da saúde, segurança, conforto e nutrição dos titulares do direito (acesso à água potável, energia para o preparo da alimentação, iluminação, saneamento básico etc.);

C) As despesas com a manutenção da moradia não podem comprometer a satisfação de outras necessidades básicas;

D) A moradia deve oferecer condições efetivas de habitabilidade, notadamente assegurando a segurança física aos seus ocupantes;

E) Acesso em condições razoáveis à moradia, especialmente para os portadores de deficiência;

F) Localização que permita o acesso ao emprego, serviços de saúde, educação e outros serviços essenciais;

G) A moradia e o modo de sua construção devem respeitar e expressar a identidade e diversidade cultural da população.

Esses elementos básicos constantes no Comentário-Geral N.4, $\S 8^{\circ}$, do Comitê da ONU, buscando estabelecer padrões internacionais em relação à adequada moradia, serão retomados no decorrer deste trabalho, pois um dos objetivos é analisar a íntima ligação do direito à moradia a outros direitos sociais prescritos no Art. $6^{\circ}$ da Constituição federal de 1988. 


\subsection{A CRISE NA APLICAÇÃO E A EXIGIBILIDADE DO CUMPRIMEN- TO DO DIREITO À MORADIA}

Ingo Wolfgang Sarlet (2003, p. 197) declara a existência atualmente de uma crise do Estado Democrático (e Social) de Direito, do Direito e dos Direitos Fundamentais no tocante a uma problemática jurídica de eficácia e efetividade dos direitos fundamentais, com especial atenção aos direitos sociais. Tal crise tem como uma das principais causas o fenômeno da Globalização econômica, que acarreta efeitos negativos sobre o Estado Democrático (e Social) de Direito ("diminuição do Estado", desnacionalização, desestatização, desregulação e redução gradativa do Estado no domínio econômico e social) e, de modo particular, sobre os direitos fundamentais. Deixa claro que também os níveis de exclusão social contribuem para esta crise.

Não obstante alertar para essa problemática (crise com efeitos sobre os direitos sociais, inclusive), reconhece Sarlet que a Constituição Federal de 1988 consagrou, ao menos na esfera jurídico-positiva, um Estado Democrático de Direito necessariamente comprometido com a justiça social.

Sarlet (2003, p. 198) coloca uma indagação acerca de quem poderá, com efetividade, proteger o cidadão e, no plano internacional, as sociedades menos favorecidas. Explica que, por conta da política e da economia do chamado "Estado mínimo", propalado pelo assim designado "consenso neoliberal", há preocupante enfraquecimento do Estado Democrático de Direito (necessariamente "amigo" dos direitos fundamentais). Fragilização esta acompanhada por um incremento assustador dos níveis de poder social e econômico exercido pelos grandes atores do cenário econômico, que justamente buscam desvencilhar-se das amarras do poder estatal.

Constata Sarlet que, somado este enfraquecimento do Estado quanto a assegurar os direitos fundamentais (entre eles o direito à moradia adequada, à saúde e à educação) ao incremento assustador dos níveis de exclusão social e à falta de capacidade prestacional dos Estados, o resultado é um elemento impulsionador, o qual agrava a crise dos demais direitos. Cita como exemplos os crescentes níveis de violência social, como os casos de agressões a bens fundamentais, como a vida e a integridade física entre outros.

Alerta ainda Sarlet $(2003$, p. 202) que a discussão em torno da eficácia jurídica e social do direito à moradia, inserido neste contexto e por ele diretamente influenciado, "não pode passar ao largo das questões-enunciados, notadamente no que diz com a capacidade de implantação por parte do Poder Público e os limites da atuação judicial no que diz com a efetivação deste direito".

Quanto à exigibilidade do cumprimento do direito à moradia, não obstante o disposto no Art. $5^{\circ}, \S 1^{\circ}$, da Constituição Federal de 1988 (as normas 
definidoras dos direitos e garantias fundamentais têm aplicação imediata), há discussão doutrinária acerca da possibilidade de se exigir do Estado, sob forma de prestação, o adimplemento dos direitos sociais, dentre eles, o direito à moradia.

Luís Roberto Barroso (2000, apud PERES, 2010, p. 76-77) trouxe um exemplo a fim de demonstrar a impossibilidade prática de se exigir do Estado o adimplemento de prestações relativas aos direitos sociais, ao menos sem uma regulamentação anterior. Barroso comentou o Art. 368 do Anteprojeto de Constituição elaborado pela Comissão de Estudos Constitucionais (Comissão Afonso Arinos, 1986). Eis o referido artigo:

Art. 368. É garantido a todos o direito, para si e para sua família, de moradia digna e adequada, que the preserve a segurança, a intimidade pessoal e familiar.

Para Barroso, supondo que tal dispositivo fosse incorporado à Constituição Federal de 1988, seria incabível, no dia seguinte à promulgação de tal texto, que o indivíduo que fosse capaz de demonstrar não possuir moradia teria direito de ação contra o Poder Público para recebê-la.

Seria insensato supor que este tenha sido o objetivo da norma. Logo, tem-se de admitir que ela não visou investir alguém no poder jurídico de exigir prontamente uma prestação positiva do Estado. [...] Assim, pode-se dizer que, enquanto não regulamentado através de políticas governamentais para o acesso à moradia, assim como as demais normas instituidoras de direitos sociais, o particular poderá apenas 'exigir' do Poder Público que se abstenha de praticar atos que contravenham os seus ditames (BARROSO, 2000, apud PERES, 2010, p. 76-77).

Jorge Miranda (1990, apud PERES, 2010, p. 79) ponderando sobre a aplicabilidade dos dispositivos constitucionais, assevera que

[...] certas normas não consentem que os cidadãos ou quaisquer cidadãos as invoquem já (ou imediatamente após a entrada em vigor da Constituição), pedindo aos tribunais o cumprimento por si só, pelo que pode haver quem afirme que os direitos que delas constem, máxime os direitos sociais, têm mais natureza de expectativas que de verdadeiros direitos subjectivos.

“Contudo, as coisas não são bem assim" (MARQUESI, 2010, p. 463). Tal afirmação deste doutrinador, de início, se refere à visão da Comissão brasileira presente à Conferência Habitat II, em Istambul (1996). Conforme Marquesi, 
"a Comissão brasileira presente ao evento, indagada, hesitou em aceitar a dicção 'direito à moradia' como parte dos anais, argumentando que isso permitiria à população ingressar com ações judiciais, exigindo-o do Estado imediatamente". São os dizeres da Comissão brasileira:

Durante os debates, concluímos que o direito à moradia é um direito de natureza programática, ou seja, será obtido progressivamente e não poderá ser cobrado na justiça (VIANA, apud MARQUESI, 2010, p. 463).

Ensina José Afonso da Silva (apud MARQUESI, 2010, p. 463) que "os preceitos constitucionais, segundo classificação universalmente aceita, refletem ou normas de eficácia contida ou normas de eficácia imediata". Sendo, conforme assinala Marquesi (2010, p. 463), a normas de eficácia contida aquelas cuja eficácia depende de lei regulamentadora; por seu turno, as de eficácia imediata são autoaplicáveis, não dependendo de edição de norma regulamentadora, vinculando, por isso, o Poder público a concretizá-las sem qualquer condição.

"Dada a natureza de direito fundamental, a moradia deve ser assegurada imediata e incondicionalmente" (MARQUESI, 2010, p. 464). Conforme este Professor, tal interpretação decorre do parágrafo primeiro do Art. $5^{\circ}$ da Constituição Federal de 1988, que determina que as normas definidoras dos direitos e garantias fundamentais têm aplicação imediata. E conclui Marquesi que

Não é de se exigir ou esperar lei ordinária de integração nem convir na protelação de uma política habitacional. Trata-se, à evidência, de norma de aplicabilidade imediata, a vincular tanto administrador e legislador, atribuindo-lhe a obrigação de criar moradias, quanto o julgador, no dever de interpretação conforme a Constituição. É que o simples enunciado da norma constante no Art. $6^{\circ}$ basta para que se conheça a intenção do legislador de obrigar os poderes públicos a conferir tratamento prioritário à moradia (MARQUESI, 2010, p. 464).

Oportuno retomar neste momento a temática da crise dos direitos fundamentais detectada por Sarlet (2003, p. 240). Sarlet, ao afirmar que tal crise é aguda em relação aos direitos sociais prestacionais, constata um impacto negativo sobre a capacidade prestacional do Estado; este vinculado diretamente a um limite fático da reserva do possível e do princípio da reserva parlamentar em matéria orçamentária. Estes atuando diretamente sobre a eficácia e efetividade dos direitos sociais.

Mesmo diante de tal contexto, devem ser observados os ditames dos 
tratados internacionais, como observa o supracitado doutrinador:

Conforme antes mencionado, cabe então ao Poder Público agir, normatizando e executando políticas de urbanização, em face da crescente urbanização, no sentido de proporcionar a máxima efetividade no tocante ao direito humano, fundamental e social à moradia. Moradia digna, adequada.

\section{O RESIDENCIAL VISTA BELA}

O conjunto habitacional Vista Bela está localizado na zona norte da cidade de Londrina, Paraná. Lá pode ser encontrada numerosa população que reside em casas populares do denominado Programa de habitação "Minha casa Minha Vida".

Conforme o sítio eletrônico do Ministério das Cidades, tais moradias foram construídas com recursos advindos do Fundo de Arrendamento Residencial (FAR), no âmbito do Programa Nacional de Habitação Urbana (PNHU), integrante este do Programa "Minha Casa Minha Vida". O FAR é destinado à construção de moradias às famílias com renda mensal de até $\mathrm{R} \$ 1600,00$. Esta é a denominada população de baixa renda.

Segundo informações fornecidas pela Companhia de Habitação de Londrina (COHAB-LD),

foram entregues um total de 2.712 unidades habitacionais, sendo: 1.206 casas geminadas, com área de $36,89 \mathrm{~m}^{2}, 46$ casas adaptadas para pessoas idosas, com área de $37,24 \mathrm{~m}^{2} ; 20$ casas adaptadas para pessoas com deficiência (PCD), com área de 49,68m², e, 1.440 apartamentos, com área de $43,21 \mathrm{~m}^{2}$.

Tal empreendimento foi considerado o "maior canteiro de obras" do Programa Minha Casa, Minha Vida, segundo matéria jornalística veiculada pelo Jornal Folha de S. Paulo em 21/10/2012.

Também foi posto nesta matéria que o Residencial Vista Bela possui um enorme contingente populacional, desprovido de serviços essenciais de saúde e educação. Eis a manchete: 'Uma 'minicidade' com cerca de doze mil habitantes, no norte do Paraná, não tem escola, creche nem posto de saúde. Comércio, só informal" (FOLHA DE S. PAULO, 2012, grifo nosso).

Deve ser posto neste trabalho que, mesmo sem o normal acesso a todos os serviços essenciais (pois há no Vista Bela serviços como rede de esgoto, água encanada, luz elétrica e até aquecedores-solar para a água do chuveiro) há moradores que reconhecem que estão atualmente em melhores condições sociais, conforme, ainda, a supracitada matéria da Folha de S. Paulo: "Apesar da ausência de infraestrutura, famílias dizem que a vida melhorou com a mudança para 
o Residencial Vista Bela, em Londrina, no Paraná. Muitas são oriundas de ocupações irregulares, invasões ou áreas de risco" (FOLHA DE S. PAULO, 2012).

Importa registrar que, conforme a COHAB-LD, foram atendidas no Residencial Vista Bela 840 famílias que residiam em áreas de ocupação irregular (fundos de vale, assentamentos e invasões).

Trata-se de uma população de considerada baixa renda, que, em sua maioria, não possui plano de saúde privado e tampouco capacidade econômica de contratar serviços particulares de ensino. "Segundo informações da Prefeitura de Londrina, 96\% das famílias do local vivem com menos de três salários mínimos mensais. As prestações pagas à Caixa [Caixa Econômica Federal] variam de R\$ 50 a R\$ 150" (FOLHA DE S. PAULO, 2012).

Os graves problemas assinalados pela Folha de S. Paulo, como a falta de escolas e de postos de saúde, comprometem o exercício do direito à moradia adequada, conforme o Comentário-Geral N.4, $\S 8^{\circ}$, do Comitê da Organização das Nações Unidas (ONU) para Direitos Econômicos, Sociais e Culturais. Entre os elementos básicos a serem atendidos no tocante ao direito à moradia adequada, deve a localização permitir o acesso ao emprego, serviços de saúde, educação e outros serviços essenciais.

Sobre as moradias proporcionadas, quanto ao tamanho delas (casas com $\left.36,89 \mathrm{~m}^{2}\right)$, pode-se chegar à conclusão de que estas casas serão inadequadas caso nelas residam famílias numerosas, como, por exemplo, famílias com seis pessoas. Por isso, alguns moradores, conforme puderam, trataram de aumentar o tamanho das casas.

O tamanho dessas moradias (casas e apartamentos), assim como outras características, está fixado em, ao menos, um patamar mínimo pelo Ministério das Cidades, como consta em seu sítio eletrônico, no tópico denominado "Especificações Mínimas". Por especificações mínimas pode ser entendido o mínimo em termos de tamanho das moradias (dimensões gerais dos cômodos) em conjunto com as características gerais dos materiais empregados na construção dos imóveis. Estas exigências constituem um "mínimo em relação ao valor máximo" estipulado pelo Ministério das Cidades para a aquisição dos imóveis pela instituição financeira oficial para a alienação aos beneficiários do Programa Minha Casa Minha Vida.

Que fique claro que não se trata aqui de desdém aos programas de habitação postos em prática pelo Poder público quanto às moradias proporcionadas. Trata-se apenas de constatar que, embora haja esforços governamentais direcionados ao atendimento do direito social à moradia, nem sempre é proporcionada a moradia considerada adequada (conforme, por exemplo, certos requisitos do Comentário-Geral N.4, $\S 8^{\circ}$, do Comitê da ONU sobre moradia adequada). O Estado Democrático Social de Direito, destinado a erradicar a pobreza e a mar- 
ginalização e reduzir as desigualdades sociais (CRFB/88, Art. $3^{\circ}$, III), concretiza uma grande evolução em relação ao Estado Liberal. As políticas que visam à efetivação dos direitos sociais almejam, por exemplo, o acesso a todos à moradia (simples que seja).

A falta de escolas, postos de saúde e outros direitos sociais atrelados ao direito à moradia serão abordados a seguir.

\subsection{O ACESSO À SAÚDE E À EDUCAÇÃO NO RESIDENCIAL VISTA BELA}

A esta altura serão abordados os direitos à saúde e à educação. São direitos sociais previstos no Art. $6^{\circ}$ da Constituição Federal de 1988, assim como o direito à moradia e outros mais. Não que sejam menos relevantes os outros direitos sociais lá positivados (fora estes, são prescritos: a alimentação, o trabalho, o lazer, a segurança, a previdência social, a proteção à maternidade e à infância, a assistência aos desamparados). Ocorre que estes outros direitos sociais não aqui abordados os serão posteriormente, até porque neles repercute, de forma negativa, a não concretização, ou deficiente efetivação do direito à moradia.

Quanto ao direito à saúde, seu acesso é direito de todos e dever do Estado, nos termos do Art. 196 da Carta de 1988, que deve garanti-lo à população mediante políticas sociais e econômicas que visem à redução do risco de doença e de outros agravos e ao acesso universal e igualitário às ações e serviços para sua promoção, proteção e recuperação. Também deve ser colocado que os cuidados com a saúde da população competem às três esferas governamentais. Trata-se de matéria de competência comum da União, dos Estados, do Distrito Federal e dos Municípios, consoante o Art. 23, II, da CRFB/88. Também determinou a Constituição Federal que a saúde fosse administrada por um Sistema Único de Saúde (SUS), vinculado ao Ministério da Saúde. Conforme o Art. 198, caput, I, II e II da CRFB/88, estes serviços integram uma rede regionalizada e hierarquizada, tendo como diretrizes a descentralização de governo, o atendimento integral, com prioridade para as ações preventivas e a participação da comunidade.

Foi acima mencionado que, em sua maioria, não podem os moradores do Conjunto Vista Bela pagar por planos de saúde privados. Resta-lhes o socorro do Sistema Único de Saúde (SUS).

As Unidades Básicas de Saúde são "a porta de entrada" do SUS. Segundo o sítio eletrônico Portal Brasil (agregador de conteúdo dos ministérios e secretarias do governo federal, com notícias diárias e serviços para o cidadão),

os usuários do SUS podem realizar consultas médicas, curativos, tratamento odontológico, tomar vacinas e coletar exames laboratoriais. 
Além disso, há fornecimento de medicação básica e também encaminhamentos para especialidades (PORTAL BRASIL, 2013).

Estas unidades têm por objetivos descentralizar o atendimento, dar acesso universal aos serviços de saúde e diminuir a demanda dos hospitais.

A Unidade Básica de Saúde (UBS) mais próxima do Residencial Vista Bela está localizada no conjunto habitacional Chefe Newton Guimarães, acerca de dois quilômetros do Vista Bela. Segundo o sítio eletrônico da Prefeitura do Município de Londrina, tal UBS tem como área de abrangência onze conjuntos habitacionais.

Às UBS cabe o atendimento a vários conjuntos habitacionais. Não seria, a priori, caso de excessiva demanda à UBS Chefe Newton a implantação de mais um conjunto habitacional em sua área de abrangência. No entanto, não foi previsível aos administradores/gestores públicos, no âmbito local e federal, o impacto causado pelo enorme e repentino crescimento demográfico resultante da ocupação do Residencial Vista Bela. Crescimento populacional que agora está demandando urgentes medidas do Poder Público, principalmente do Poder Público do Município de Londrina, onde está a população envolvida (a qual sofre as consequências), além da imprensa jornalística que faz questão (e deve) de mostrar diuturnamente as reclamações e as mazelas resultantes aos moradores.

Neste contexto, assiste mencionar mais um trecho da anteriormente citada matéria da Folha de S. Paulo (21/10/2012) ao "calcular o preço da distância" pago pelos moradores do Residencial Vista Bela: "Outro drama é a falta de posto médico. Quem precisa recorre ao posto do bairro vizinho [Chefe Newton], distante $2 \mathrm{~km}$ e que não atende à demanda" (FOLHA DE S. PAULO, 2012).

Quanto ao direito à educação básica aos moradores do Residencial Vista Bela pode-se afirmar, sem medo de errar, que se trata atualmente de direito de difícil acesso.

Foi aqui citado que o direito à educação está inserido no Art. $6^{\circ}$ da CRFB/88. Consoante o Art. 205 da CRFB/88, a educação é direito de todos e dever do Estado e da família. Há o dever imposto ao Estado de promover a educação, efetivando-a mediante a garantia de educação básica obrigatória e gratuita a todos, dos 4 (quatro) aos 17 (dezessete) anos de idade, assegurada inclusive sua oferta gratuita para todos os que a ela não tiveram acesso na idade própria (CRFB/88).

A educação básica (obrigatória) é dividida em três níveis: infantil, fundamental e médio. A educação infantil deve ser ofertada em creches e pré- escolas às crianças de até 05 anos de idade (art. 208, IV, CRFB/88). A educação fundamental (obrigatório), nos termos do Art. 32 da Lei N. 9394/96, com duração de 9 (nove) anos, gratuita na escola pública, iniciando-se aos 6 (seis) anos 
de idade e tendo por objetivo a formação básica do cidadão. Quanto ao ensino médio (também obrigatório), este com duração mínima de três anos.

No tocante à educação infantil, esta deve ser ministrada e garantida por meio dos Centros de Educação Infantil (CEI).

Conforme notícia publicada em 28 de janeiro de 2013 no Portal eletrônico odiario.com, de autoria de Juliana Leite, foi implantado no Residencial Vista Bela o primeiro CEI, com 160 vagas para crianças de 04 (quatro) a 05 (cinco) anos. Ainda conforme esta notícia, afirmou o diretor desta unidade escolar, José Aparecido da Silva, ao declarar acerca da previsão de escolas no local, que "há projetos da Educação, mas por enquanto vamos ter as 160 vagas para a educação infantil. Já é um começo poder atender e cobrir essa necessidade".

Pode-se concluir, pelo exposto no parágrafo acima, que todas as crianças de 0 (zero) a 03 (três) anos que vivem no Vista Bela não têm acesso (ao menos lá) à educação infantil. Quiçá algumas delas sejam assistidas fora/longe do Residencial; e provavelmente muitas estão fora dos CEI. Das palavras do diretor do CEI no Vista Bela se extrai a conclusão de que a demanda por vagas é bem maior que as ofertadas à população local.

Registre-se ainda que, no Conjunto Habitacional Maria Celina, localizado próximo ao Residencial Vista Bela, foi paralisada a construção de um CEI, e que, devido a esta paralisação e posterior abandono das obras, vândalos praticaram grande depredação na construção, a qual se encontrava em adiantada fase.

Quanto ao acesso à educação fundamental e ao ensino médio, não há escolas no populoso residencial.

Conforme o Jornal Folha de S. Paulo, de 21/2012, devido à falta de escolas no Vista Bela, o Poder Público do Município de Londrina, de forma emergencial, celebrou contrato com empresa de ônibus para levar e buscar cerca de mil crianças a 23 (vinte e três) colégios espalhados por Londrina.

Ainda segundo a Folha de S. Paulo, trata-se de prestação de serviço que custa mensalmente $\mathrm{R} \$ 128$ mil e que passará de $\mathrm{R} \$ 1$ milhão até que o residencial ganhe escolas, o que deve ocorrer só no final de 2013.

Em virtude desta previsão, "até que o residencial ganhe escolas, o que deve ocorrer só no final de 2013" (matéria jornalística publicada em 21/10/2012), cumpre alertar aqui que até a presente data (junho de 2014) não se vê no Vista Bela nenhuma escola para o ensino fundamental e/ou médio em construção.

Pode-se então chegar ao seguinte raciocínio: sendo o acesso ao ensino obrigatório e gratuito direito público subjetivo (Art. 208, $\S 1^{\circ}, \mathrm{CRFB} / 88$ ), e que o não oferecimento do ensino obrigatório pelo Poder Público, ou sua oferta irregular, importa responsabilidade da autoridade competente (Art.208, $\S 2^{\circ}$, CRFB/88), a supracitada contratação emergencial, com a finalidade de levar os jovens do Vista Bela às escolas, garantiu provisoriamente o direito deles à educa- 
ção, como também serviu de alento ao pressionado Poder Público local.

Por derradeiro, e resumidamente, importa mencionar que a Assistência Social deve ser prestada a quem necessitar; é direito do cidadão e dever do Estado; trata-se de Política de Seguridade Social não contributiva, que provê os mínimos sociais, nos termos do Art. 203 da Constituição Federal de 1988 e da Lei N. 8742/93.

Uma das funções da Assistência Social é promover as ações e programas de transferência de renda aos que mais precisam, como por exemplo, o Programa Bolsa Família, do Governo Federal, criado por meio da Lei N. 10.836/2004.

Sobre os benefícios do Programa Bolsa Família, frise-se que estes são atrelados às condicionalidades. Os beneficiários têm que cumprir certas condições para que tenham direito aos benefícios, quais sejam, conforme o Art. $3^{\circ}$-A da Lei N. 10.836,

A concessão dos benefícios dependerá do cumprimento, no que couber, de condicionalidades relativas ao exame pré-natal, ao acompanhamento nutricional, ao acompanhamento de saúde, à frequência escolar de $85 \%$ (oitenta e cinco por cento) em estabelecimento de ensino regular, sem prejuízo de outras previstas em regulamento (LEI N. 10836/2004, ART. $3^{\circ}-$ A).

Em virtude do que foi exposto acerca da Assistência Social, do Programa Bolsa família e de suas condicionalidades, oportuno mencionar novamente o contrato emergencial celebrado entre o Município de Londrina e a empresa de ônibus para o transporte dos estudantes do Vista Bela. Se não fossem oferta dos ônibus aos moradores, provavelmente não seria alcançado o índice de frequência escolar de $85 \%$ exigido à manutenção dos benefícios do Programa Bolsa Família. Estaria o Estado então obstaculizando benefícios à população vulnerável, por situações de vulnerabilidade que ele (Estado) criou ao destinar a esta população moradias inadequadas, tomando-se como parâmetro, novamente, o Comentário-Geral N.4, $\S 8^{\circ}$, do Comitê da ONU.

\section{CONSIDERAÇÕES FINAIS}

O trabalho teve por objetivos principais a abordagem ao direito social à moradia em conjunto com outros direitos sociais constitucionalmente previstos, além de promover a análise de um caso concreto: o Residencial Vista Bela, em Londrina-Paraná.

Inicialmente foi tratado o direito à moradia em si. A classificação deste direito (direito humano, fundamental e social), seu reconhecimento no plano internacional e no ordenamento jurídico brasileiro, e sua exigibilidade perante o 
Estado foram alguns dos assuntos enfrentados.

Posteriormente, de posse do conceito denominado "moradia adequada", serviu este estudo a demonstrar a necessária ligação e interdependência entre o direito à moradia e os outros direitos sociais gravados no Art. $6^{\circ}$ da Constituição Federal de 1988. Foi dada ênfase aos direitos à saúde e à educação, com a intenção de constatar a situação dos moradores do Residencial Vista Bela.

Foi então verificado que o direito à moradia é devido a todos. Trata-se de um direito e fundamental prescrito no Art. $6^{\circ}$ da Constituição federal de 1988 , mas que, devido à omissão no texto constitucional e na legislação infraconstitucional, deve ser analisado sob a luz dos tratados e outros documentos internacionais a fim de se desvendar o que venha a ser considerada uma moradia adequada.

Quanto ao Residencial Vista Bela, chegou-se ao entendimento [fundamentado em pesquisas bibliográficas, coleta de dados fornecidos pelo Poder Público (COHAB-LD), além da contribuição da Imprensa (jornais online)] de que lá o direito à moradia adequada não foi efetivado. $\mathrm{O}$ direito à moradia foi assegurado, mas de forma irregular, pois enorme contingente populacional foi lá inserido, mas desprovido de serviços essenciais de saúde e educação. Lembrando-se mais uma vez que a localização das residências deve permitir o acesso ao emprego, serviços de saúde, educação e outros serviços essenciais, conforme o Comentário-Geral N.4, §8 $8^{\circ}$, do Comitê da ONU para Direitos Econômicos, Sociais e Culturais, que traz um rol de elementos básicos a serem atendidos no tocante à habitação considerada adequada.

Em face do atual contexto do Residencial Vista Bela, cabe ao Poder Público agir rapidamente no sentido de proporcionar aos moradores o devido acesso aos serviços de saúde e educação. Por "devido acesso" a estes serviços deve ser entendido algo mais que a implantação de um CEI que não garanta o efetivo acesso à educação infantil, assim como o paliativo fornecimento de transporte escolar aos jovens do Vista Bela.

Como remate, cumpre reconhecer e enaltecer (apesar do ocorrido aos moradores do Vista Bela) os esforços governamentais dirigidos à concretização do direito à moradia. Conforme o preâmbulo da $\mathrm{CRFB} / 88$ trata-se da atuação do Estado Democrático Social, destinado a assegurar os direitos sociais, e que tem como objetivos fundamentais (Art. $3^{\circ}$, I, II, III, CRFB/88) construir uma sociedade livre, justa e solidária, garantir o desenvolvimento nacional e erradicar a pobreza e a marginalização e reduzir as desigualdades sociais e regionais, promovendo o bem de todos. 


\section{REFERÊNCIAS}

BRASIL. Constituição Federal (1988). Constituição da República Federativa do Brasil. Brasília: Senado Federal. Disponível em: <http://www.senado.gov. br/legislacao/const/>. Acesso em: 10 abr. 2013.

Decreto $n^{0}$ 591, de 6 de Julho de 1992. Atos Internacionais. Pacto Internacional sobre Direitos Econômicos, Sociais e Culturais. Promulgação. Presidência da República. Casa Civil. Subchefia para Assuntos Jurídicos. Disponível em: < http://www.planalto.gov.br/ccivil_03/decreto/1990 1994/ D0591.htm>. Acesso em: 20 jul. 2013.

Lei no 8.742, de 07 de dezembro de 1993. Dispõe sobre a organização da Assistência Social e dá outras providências. Presidência da República, Casa Civil. Subchefia para Assuntos Jurídicos. Disponível em: $<$ http://www.planalto. gov.br/ccivil_03/leis/18742.htm>. Acesso em: 23 out. 2013.

. Lei no 9.394, de 20 de dezembro de 1996. Estabelece as diretrizes e bases da educação nacional. Presidência da República, Casa Civil. Subchefia para Assuntos Jurídicos. Disponível em: < http://www.planalto.gov.br/ccivil_03/ leis/19394.htm>. Acesso em: 10 out. 2013.

. Lei no 10.836, de 09 de janeiro de 2004. Cria o Programa Bolsa Família e dá outras providências. Presidência da República, Casa Civil. Subchefia para Assuntos Jurídicos. Disponível em: $<$ http://www.planalto.gov. br/ccivil_03/_ato2004-2006/2004/lei/110.836.htm>. Acesso: em 23 out. 2013.

. Ministério das Cidades. Habitação - Minha Casa, Minha Vida Fundo de Arrendamento Residencial. Disponível em: $<$ http://www.cidades. gov.br/index.php/minha-casa-minha-vida.html>. Acesso em: 18 out. 2013.

\section{. Programa Minha Casa, Minha Vida ergue "minicidade" isolada.} Folha de S. Paulo, 21 out. 2012. Disponível em: <http://www1.folha.uol.com. br/cotidiano/1172645-programa-minha-casa-minha-vida-ergue-minicidadeisolada.shtml>. Acesso em: 15 out. 2013.

LEITE, Juliana.Primeira creche do Vista Bela, em Londrina, deve funcionar no dia 18 de fevereiro. Disponível em: $<\mathrm{http}$ //londrina.odiario.com/londrina/noticia/721045/ creche-do-vista-bela-comeca-a-funcionar-em-fevereiro/>. Acesso em: 20 out. 2013. 
LONDRINA. Prefeitura do Município. Unidades Básicas de Saúde - Norte UBS - Chefe Newton. Disponível em: <http://www.londrina.pr.gov.br/index. php?option $=$ com_content\&view $=$ article\&id $=109 \&$ Itemid $=130 \&$ limitstart $=2>$. Acesso em: 15 out. 2013.

MARQUESI, Roberto Wagner. Moradia: um direito Fundamental (A Inconstitucionalidade do Art. $3^{\circ}$, VII da Lei 8.009/90). Revista Jurídica Cesumar - Mestrado, v. 10, n. 2, p. 457-472, jul./dez. 2010. Disponível em: $<\mathrm{http} / / / w w w . u n i c e s u m a r . e d u . b r / p e s q u i s a / p e r i o d i c o s /$ index.php/revjuridica/ article/viewFile/1554/1169>. Acesso em: 18 fev. 2014.

ONU- Declaração Universal dos Direitos Humanos. Adotada e proclamada pela resolução 217 A (III) da Assembleia Geral das Nações Unidas em 10 de dezembro de 1948. Disponível em: <http://portal.mj.gov.br/sedh/ct/legis_intern/ ddh_bib_inter_universal.htm>. Acesso em: 05 out. 2013.

OYAMA, Lurdes Keiko. A Constituição brasileira e a educação. Revista de Direito Educacional, São Paulo, Revista dos Tribunais , v. 5, p. 19-39, jan./jun. 2012.

PERES, Tatiana Bonatti. Direito à moradia. Revista de Direito Privado, São Paulo: Revista dos Tribunais, n. 42, p. 71-90, abr./jun. 2010.

PORTAL BRASIL. Usuários do SUS serão atendidos em unidades próximas a seus domicílios. Disponível em: <http://www.brasil.gov.br/saude/2011/09/ usuarios-do-sus-serao-atendidos-em-unidades-proximas-a-seus-domicilios $>$. Acesso em: 16 out. 2013.

SARLET, Ingo Wolfgang. O direito fundamental à moradia na Constituição: algumas anotações a respeito de seu contexto, conteúdo e possível eficácia. Revista de Direito do Consumidor, São Paulo: Revista dos Tribunais, n. 46, p. 193-244, abr./jun. 2003.

\section{THE SOCIAL RIGHT TO HOUSING AND ITS NECESSARY CONNECTION TO OTHER SOCIAL RIGHTS: ANALYSIS OF RESIDENCIAL VISTA BELA IN LONDRINA - PARANA}

ABSTRACT: The right to housing is a fundamental right formally laid down in Article 6 of the 1988 Federal Constitution that does not become effective only by building houses. Thus, it is important to unveil the concept of "adequate 
housing", covering, in addition to housing, other essential elements such as the "normal" access to health and education services, among others. For this work, the Residencial Bela Vista in Londrina, Paraná, was used as the research object, with the purpose of promoting a qualitative and quantitative research, as far as possible, using the hypothetical deductive method. This residential area is part of a public program for affordable housing that has become known in the region of Londrina exactly for it having been delivered with a blatant disregard to what one can mean by "adequate housing".

KEYWORDS: Adequate Housing; Residencial Bela Vista.

\section{EL DERECHO SOCIAL A LA VIVIENDA Y SU CONEXIÓN NECESARIA A OTROS DERECHOS SOCIALES: ANÁLISIS DEL RESIDENCIAL VISTA BELA EN LONDRINA-PARANÁ}

RESUMEN: El derecho a la vivienda es un derecho fundamental, establecido formalmente en el artículo $6^{\circ}$ de la Constitución Federal de 1988, que no se hace efectiva sólo con la construcción de residencias. Importa entonces desvendar el concepto de "vivienda adecuada", que abarca, además de la vivienda, otros elementos esenciales, como el acceso "normal" a los servicios de salud y educación, entre otros. Para este trabajo, se ha utilizado como tema de investigación el Residencial Vista Bela, en Londrina, Paraná, con el intuito de promover una investigación cualitativa y cuantitativa, en la medida de lo posible, utilizando el método hipotético deductivo. Este residencial es parte de un programa público de viviendas populares que se ha quedado conocido en la región de Londrina, exactamente por haber sido entregue con flagrante desprecio a lo que se puede entender por "vivienda adecuada".

PALABRAS CLAVE: Vivienda adecuada; Residencial Vista Bela. 